\title{
Introduction. Asia-Europe dialogue on norms: revisiting the role of norm-receivers in the conceptualisation of the 'normative power Europe'
}

\author{
Natalia Chaban ${ }^{1}$ - Annick Masselot ${ }^{1}$. \\ Katharine Vadura ${ }^{1}$
}

Published online: 10 May 2015

C) Springer-Verlag Berlin Heidelberg 2015

\section{Contextualising the special issue}

This special issue sets out to explore the responses of norm-receivers to EU export of norms and values. The main focus of this special issue is on the Asian recipients of EU norms. The leading theoretical explanations - used by all contributors to this Issueare from the revisited analytical framework of 'Normative Power Europe' (NPE). NPE is a popular conceptual paradigm that has informed debate about the EU since the early 2000s. Introduced in the seminal work by Ian Manners (2002), it remains a useful and intellectually attractive model to understand the EU and its actions both internally and externally. Its appeal lies in its emphasis on ideas; its open, eclectic and critical nature; and its focus on explanations of power beyond state-centred models.

In recent times, there appears to be a divergence of views with regard to the attractiveness, role and importance of NPE as a vehicle for deeper understanding of the EU and its actions. For some, the appeal of the NPE approach is waning (Nicolaïdis and Whitman 2013). For others, substantial revisions are needed (Whitman 2013). This situation is not in the least due to the fact that the topography of the NPE scholarly debate features a number of blind spots. The most recent attempts to map the NPE legacy (Nicolaïdis and Whitman 2013; Björkdahl et al. 2015) indicate a distinct analytical terra incognita, namely conceptualisation of the receiver of the NPE messages. While the majority of NPE scholarship has been - and remains - Eurocentric, there is a growing demand to understand the factor of external norm-takers in a

Natalia Chaban

natalia.chaban@canterbury.ac.nz

Annick Masselot

annick.masselot@canterbury.ac.nz

Katharine Vadura

katharine.vadura@canterbury.ac.nz

1 University of Canterbury, Christchurch, New Zealand 
normative dialogue project by the EU. This special issue explores conditions under which the receivers of EU normative messages - in our case, those located in Asiacould actually become 'takers' of norms from the EU. Underpinning this question is an assumption of the agency of norm-receivers that is filtered through local political, socioeconomic and cultural conditions; histories; traditions; images of self and perceptions of others. Therefore, in this introduction, we use the term 'norm-receivers' as this acknowledges the potential for different outcomes in the norm-reception process.

The complex dynamics of a changing world invite revision of the EU's self-image as a global 'normative' power. Of special note for us is the growing self-confidence of many global actors who refuse to be passive targets of ideas diffused by the EU. Agency is thus a key factor behind the range of reactions to the EU as a sender/diffuser of norms and values. As this volume will show, the notion of agency is itself highly contested within the context of NPE. Reactions arguably occupy the continuum from adaption and adoption to resistance and rejection (Björkdahl et al. 2015). Importantly, these reactions were found to oscillate between the different modes and often explicated hybrid/blended characteristics. In addition, the context, connections and standpoints taken in relation to norms and values need further examination. For example, a receiver may react positively to some diffused norms and negatively to others. Moreover, positive and negative reactions to the same norm by the same actor may also coexist. Björkdahl et al. (2015) called for their analytical model to be tested in a more systematic manner through location-specific cases. Our special issue responds to this call and explores agency and a range of reactions among norm-receivers in the geopolitical region of Asia.

We define 'Asia' in a broad geographical sense - 'the largest of the continents, bordering on the Arctic Ocean, the Pacific Ocean, the Indian Ocean, and the Mediterranean and Red Seas in the west' (Collins Dictionary, on line). ${ }^{1}$ Guided by this definition, the collection of articles in this issue elaborates insights from Northeast, South, Southeast and West Asia as well as Eurasia. Bringing the receiver to the frontstage of the NPE approach, case-studies in this issue explore reactions from China, Japan, South Korea, India, Thailand, Singapore, Indonesia, Myanmar/Burma, Malaysia as well as Israel and Russia. Asia is rapidly changing-Asian actors in their various guises are characterised by growing economic capacities, increasing political confidence and improving standards of living. Many commentators point to the on-going concentration of 'emerging' capabilities in this geopolitical region (e.g. Masselot 2013). It is predicted that 'rising' Asia will become a more critical receiver of the EU's messages - normative or otherwise. Commentators also detect early indications of foundational shifts in established norms and values. Scholars, however, critically question how much the change can be attributed to the EU and how much stems from other exogenous factors. Perhaps the most relevant consideration for this special issue is the fact that Asia is increasingly becoming a sender of its own normative agenda quite independent of any EU messages. Lastly, this development is not only due to the

\footnotetext{
${ }^{1}$ Collins dictionary further elaborates this definition: 'It includes the large peninsulas of Asia Minor, India, Arabia, and Indochina and the island groups of Japan, Indonesia, the Philippines, and Sri Lanka; contains the mountain ranges of the Hindu Kush, Himalayas, Pamirs, Tian Shan, Urals, and Caucasus, the great plateaus of India, Iran, and Tibet, vast plains and deserts, and the valleys of many large rivers including the Mekong, Irrawaddy, Indus, Ganges, Tigris, and Euphrates. Pop: 4164252000 (2011 est). Area: 44391162 sq km (17 139445 sq miles)'
} 
EU's own internal problems which have been aggravated by the prolonged Eurozone sovereign debt crisis and the EU's political hesitation and inaction surrounding the most recent dramatic events in its neighbourhood (Ukraine's crisis/Gaza/Israel/Bengazi).

The analytical focus on the receiver was instrumental in revealing a range of reactions towards the NPE messages among its various Asian partners. While positive reactions featured adoption and adaption, the negative reactions oscillated between resistance, vociferous rejection, and even indifference, accompanied by scepticism and criticism. Reflecting on these two modalities, contributors consider different explanations and revisit and, in turn, advance the theoretical model of NPE.

\section{Revisiting the NPE model}

In his seminal work, Manners proposed to conceptualise NPE as being grounded in the three characteristics - a power that has,

ontological quality to it - that the EU can be considered a changer of norms in the international system; a positivist quantity to it - that the EU acts to change norms in the international system; and a normative quality to it - that the EU should act to extend its norms into the international system (Manners 2002, 253).

Predictably, those questions such as 'What the EU is?', 'What the EU does?' and 'What impact it has?' - that have led the inquiry into the NPE for more than a decadereceive attention in this volume. The analytical focus on the external receiver also allows us to develop a set of additional enquiries. This issue confirms Kavalski's argument (2013) which extends the paradigm of understanding the EU's dialogue with the world from exploring 'What the EU is?' and 'What the EU does?' to 'How the EU is recognised?' and 'Why is the EU recognised that way?' Focus on external receivers also prioritises the key question 'What impact the EU has?' and suggests follow up inquiries - 'What the EU should be?', 'What impact it should have?' and 'In whose eyes?' Contributions to this volume argue that a parallel set of the same questions exists on the receivers' side, and any effective normative dialogue must account for those.

Contributors to the special issue differentiated between norm-receivers' reactions to different types of exported norms and interactions between those types - cosmopolitan/ moral, liberal/market and legal (Garcia and Masselot, Orbie and Khorana, Pardo and Gordon, and Hopkins). Firth, Stumbaum and Vadura all explore the process of transmitting normative messages from the sender to the receiver contemplating under what condition a positive reaction of adoption or adaption is likely to take place. Finally, norm-receivers' cognitions and perceptions of the sent norms and of the norm-sender as another key to understanding the range of reactions when norms are imported are explored (Chaban and Holland, Headley and Shen). These three areas remain underresearched in the NPE scholarship, and this special issue addresses these deficits.

\section{The substance of norms and norm reception}

The research featured in this collection points to a distinct conflict between messages on the EU's ideational normative position and messages on the EU's economic 
position. For Garcia and Masselot, who consider Asian reactions to the transfer of social norms and legislation within the frameworks of various EU-Asia Free Trade Agreements, the focus is on the conflict between EU norms and values on the one side and economic interests through the promotions of economic growth and priority of trade on the other. Their conclusion confirms the strong agency of the Asian normtakers used to resist the EU's intentions to diffuse social norms through trading mechanisms. At the same time, Garcia and Masselot depict the positive reception contained in the normative dialogue between the EU as a sender and an external Asian partner (Malaysia) as a norm-taker which has resulted in revision of an outdated law and update of local legislation.

Orbie and Khorana take the next step and propose to move beyond opposition between norms vs. economic interests. They invite the reader to instead consider a complex interweaving of interest-based and ideational elements in EU actions beyond its borders. Exploring the uneasy negotiations surrounding EU-India Free Trade Agreement, and India's reaction to the EU's pressure in the field of government procurement and human rights, the authors propose the examination of a previously overlooked concept of the substance of EU norms. With this, Orbie and Khorana extend the arsenal of EU norms including a nuanced distinction between cosmopolitan liberal norms and liberal market norms. Their argument leads to the conclusion that the EU is not always able to promote both types of norms through trade-related interactions.

Pardo and Gordon echo Garcia and Masselot in their depiction of a hiatus between the normative and economic positions of the EU. Exploring the case-study of Israel as a norm-taker, the authors parallel Orbie and Khorana's central argument and distinguish between the EU's 'core' norms and 'economic' norms. Pardo and Gordon also suggest more nuances to understand the separation between the processing EU interest-based and ideational messages. According to Pardo and Gordon, there is a separation between the economic interests of the EU member states and the normative position of the EU as a whole. In this argument, the member state level allows the EU to strike trade relations with external partners who violate 'core' norms, while the reiteration of 'core' norms at the EU level is an instrument for the creation and support of internal European identity rather than a tool for diffusing norms externally. The authors argue that when 'core' norms coincide with economic interests of the member states, those norms are more readily diffused. For the receiver, the uptake of norms is notably stratified and varied: economic norms are found to be readily adopted and adapted within government bureaucracy, and the 'core' norms are observed to have a limited positive reaction from the non-government sector. Attention to norm-taking among different decision-, policy- and opinion-making cohorts is thus required. This is explored in the paper by Chaban and Holland in this issue. In their conclusion, Pardo and Gordon stress that norm-receivers are not a homogenous group, and calls for a more precise conceptualisation of how the receivers are stratified.

The idea of the 'core' norms being instrumental primarily for the EU's internal identity is also developed by Hopkins. In his examination, he focuses in on yet another type of exported norms: legal norms. Hopkins treats EU member states' determination to agree to and uphold supranational legal norms as a critical condition for the EU to preserve its identity and survive numerous crises. According to Hopkins, this internal 'core' norm is often overlooked by external receivers who attempt to emulate the EU as a successful model for regional integration (case-study ASEAN). 


\section{Cultural filters: external perceptions and recognition}

As mentioned above, our focus on the norm-receivers led to developing a new conceptual dimension in the NPE debate-'how the EU appears to be' from the perspective of the external norm-receivers. As discussed, it goes beyond the key questions 'what the EU does?' and 'what the EU is?' which dominated the earlier debate on the EU's normative qualities. In this vein, Chaban and Holland advance a concept of the cultural filters argued to be vital in reinvigorating the NPE debate from the receiver's perspective. External perceptions of the EU as a 'normative power' are assumed to be one effective cultural filter shaping norm-receivers' reactions. Using the open and eclectic nature of the NPE approach, Chaban and Holland propose to link the approach with another influential theoretical model — cascade activation framing. Popular in communication studies, this theory proposes an explanation on how ideas about a foreign policy and international actors are spread within local societies. With the theory prioritising the role of the newsmakers in the activation of ideas, Chaban and Holland studied perceptions of the EU as an NPE among Asian journalists and media gatekeepers (editors, news directors and producers). Chaban and Holland found some evidence of positive perceptions of the EU as a sender of the NPE messages: a high intensity of those perceptions was found among the Japanese newsmakers, and positive but low-intensity views were observed in Singapore. Yet, other locations in the study were different in their perceptions - media people in South Korea and China expressed neutral low-intensity perceptions, while Thailand and Indonesia featured low-intensity negative views, and Indian newsmakers expressed high-intensity extremely ambivalent opinions on the NPE.

Their study's findings echo the findings by Orbie and Khorana, who also noted that India's rejecting reactions to the EU's normative pressures through the FTA negotiations is ultimately underlined by perceptions of the EU being a protectionist entity having a patronising Eurocentric attitude towards the largest world democracy. Similarly, Garcia and Masselot reported that the EU as a normsender is often seen as an actor with ulterior motives coming from a protectionist stand-point. Pardo and Gordon also pointed at the clash between the EU's selfvision in terms of its normative cache and how Israelis and Palestinians perceived the EU's normative position.

The importance of external recognition of the sender of the 'normative' messages is also argued by Headley. Focusing on the EU-Russia interactions, his paper considers 'cultural filters' on the Russian side which recognise the content of both moral/ cosmopolitan or economic/liberal/market norms as appropriate. However, it is the authority of the sender - the EU— to disseminate these norms upon the norm-receiver's that is questioned in the case of Russia. Headley's paper raises two important points. Firstly, the perception of credibility and legitimacy of the sender of the 'normative' message vis-a-vis the self-visions of the receiver to be recognised as a critical cultural filter. Stumbaum also considers cultural filter and reveals their hindrance in the diffusion of template, know-how and other processes in the area of security and defence. Secondly, the paper highlights the idea of 'globalisation of the norms'. The norm-receivers may already see themselves as 'citizens of the world', and through this identification, they are less resistant to the content of the norms, as they see themselves able to undertake those norms. 
A similar idea was shared in the paper by Shen who elaborates the case-study of yet another 'emerging' power-China. The paper factors in cultural/historical filters and the Chinese particularities when China receives and reacts to the norms sent by the EU. In particular, the paper claims that the Chinese utilise their Chinese particularities cleverly to escape implementing universal values such as human rights/death penalty abolition. Echoing the argument by Headley, Shen's analysis focuses on how China uses the claim to moral authority (similar to Russia) as a tactic to avoid addressing human rights.

In their explorations of the cultural filter, several contributions to this volume advocate a need for historical insights. Those are seen as the key to understand norm-receivers' modern-day reactions to the EU's normative messages. In this light, Garcia and Masselot follow the development of EU social values within the community and trace the main steps of its externalisation. Pardo and Gordon consider in detail interactions between the EU and Israel since the inception of the then European Community. Orbie and Khorana account for Europe's colonial legacies in their discussion. Stumbaum highlights that assumptions of hindrance on cooperation due to historical legacy are not in fact influencing strongly the area of norm transfer in the peacekeeping and security fields. Shen echoes this idea and suggests that historical legacy is a vehicle that is used strategically in the dialogue on norms on human rights and death penalty abolition between China and the EU.

\section{Understanding the process of communication}

The final element addressed in this volume is the process of transmission of the original message and messages about reception. Firth argues the centrality of the process in the interaction between the norm-senders and norm-receivers and explores under what condition the process results in a positive reception. Analysis of the vast network of international laws and treaties considered in her paper suggests that market norms are not just sent and received unchanged, but, using the analogy of viral transmission, could be adapted and then re-transmitted.

The paper by Stumbaum also focuses on the process of diffusion. It shows that difficulties of norm transfers are not only a product of distance but also a result of the specific policy field. In the area of security, the EU inevitably has a limited role for the incentive 'market access' as well as a limited capability for force projections. The implication of cultural filters limit further any attempts at diffusion of standardised norms especially in sensitive areas such as defence and security.

The contribution by Vadura on the EU as a 'norms entrepreneur' for human rights tackles the question of the EU as a norms-sender in the technological realm. In analysing the EU's presence in the use of digital diplomacy for human rights advocacy - a non-hierarchical medium of communication - the EU was seen to be visible as an 'inadvertent' norms entrepreneur in its operational pursuit of being an entrepreneur for social good. The reduction of the distance advocated by Vadura gives a new twist to NPE. She highlights how the change in technology also allows the EU to directly reach the people in third countries through digital media. In that sense, this is viewed as a tool for 'people power'. Thus, NPE is far from dead or dying, as claimed by some. The digital revolution has potential for the EU NPE. This development might also overcome some of the cultural filter issues. 


\section{Concluding remarks}

This special issue claims that NPE is far from dead. Our focus on receiversoverlooked for some time-promises new puzzles in developing NPE conceptual approach. Research cases featured in this special issue point to the fact that normreceivers' reactions are location-bound. The 'tyranny of distance' should not be overemphasised. Other important factors include 'norms and values kinship' and digital revolutions that seem to collapse the distances. Reactions are also time-specific and historically conditioned. They are cohort-specific and sieved though numerous cultural filters (including perceptions). They are conditioned by the norms' substance (market/ economic, cosmopolitan/moral and legal norms) and issue-areas (e.g. security, trade, etc.). Reactions are also partially shaped by the medium the in-coming message is transmitted through.

We argue that any informed discussion on post-crisis EU as a norm-sender and external partners as norm-receivers possessing agency should include these variables to unpack the complex dynamic of norm exports and imports. Asia is a fruitful location for exploring NPE because it presents itself as a global economic force and is aware of its own potential as a region and also as individual states. The relationship between the EU and Asia is in some cases relatively young, and it appears to be driven by the friction between forces or equal of similar nature.

Contributions to this volume - undertaken from an analytical point of 'normative' inquiry towards the receiver -indicate the scope for future research that lies in exploration of the complex interactions between several relations: The first being the relation between norm-sender's and norm-receivers' self-images; the second, between normreceivers' self-images and the receivers' perceptions of the norm-sender; and the third, between receiver's self-images and receivers' perception of norms and values.

\section{References}

Björkdahl A, Chaban N, Leslie J and Masselot A (eds) (2015) Importing EU norms? Conceptual framework and empirical findings. Springer

Collins Dictionary, Asia, http://www.collinsdictionary.com/dictionary/english/asia. Accessed 17 Nov 2014

Manners I (2002) Normative power Europe: a contradiction in terms? J Common Mark Stud 40(2):235-258

Masselot A (2013) Does the European union 'walk the walk' or just 'talk the talk' of gender equality in water development projects in the Asian region. J Gend Water 2 wH2O:8-14

Nicolaïdis K, Whitman R (2013) Preface. Coop Confl 48(2):167-170

Whitman R (2013) The neo-normative turn in theorising the EU's international presence. Coop Confl 48(2): $171-193$ 